Article

\title{
Supporting Design Optimization of Tunnel Boring Machines-Excavated Coal Mine Roadways: A Case Study in Zhangji, China
}

\author{
Bin Tang ${ }^{1,2,3, *}$, Hua Cheng ${ }^{2, *}$, Yongzhi Tang ${ }^{4}$, Tenglong Zheng ${ }^{2}$, Zhishu Yao ${ }^{2}{ }^{\circledR}$, \\ Chuanbing Wang ${ }^{3,4}$ and Chuanxin Rong ${ }^{2}$ \\ 1 State Key Laboratory of Mining Response and Disaster Prevention and Control in Deep Coal Mines, \\ Anhui University of Science and Technology, 168 Taifeng St, Huainan 232001, China \\ 2 School of Civil Engineering and Architecture, Anhui University of Science and Technology, 168 Taifeng St, \\ Huainan 232001, China; shlzheng@aust.edu.cn (T.Z.); zsyao@aust.edu.cn (Z.Y.); chxrong@aust.edu.cn (C.R.) \\ 3 Ping'an Coal Mining Institute of Engineering Technology Co., Ltd., No. 6 Building, Zhihui Valley, \\ Huainan 232001, China \\ 4 Huainan Mining Industry (Group) Co., Ltd., No. 1 Dongshanzhong Rd, Huainan 232001, China; \\ tang_yz1962@163.com (Y.T.); cbwang_hmi@163.com (C.W.) \\ * Correspondence: btang@aust.edu.cn (B.T.); hcheng@aust.edu.cn (H.C.); Tel.: +86-554-6668713 (B.T.)
}

Received: 17 October 2019; Accepted: 20 December 2019; Published: 1 January 2020

\begin{abstract}
Tunnel Boring Machines (TBMs) are a cutting-edge excavating equipment, but are barely applied in underground coal mines. For TBM excavation projects involving the Zhangji coal mine, the surrounding rock properties, stress field, cross section geometry, as well as the excavation-induced stress path of TBM-excavated coal mine roadways are different from those of traditional tunnels or roadways. Consequently, traditional roadway supporting technologies and experiences cannot be relied on for this project. In order to research an appropriate supporting pattern for a TBM-excavated coal mine roadway, first of all, the constitutive model of roadway surrounding rocks was derived, and a rock failure criterion was proposed based on rock mechanical tests. Secondly, a three-dimension finite element model was established and computer simulations under three different supporting patterns were conducted. Stress redistribution, roadway convergence, and excavation damage zone ranges of surrounding rocks under three different support patterns were analyzed and an optimal support design of the TBM-excavated roadway was made based on simulation results. During roadway excavation, convergence gauge and rock bolt dynamometers were installed for monitoring roadway convergence and the axial forces of rock bolts. The in-situ monitoring results verified the validity of roadway supporting designs.
\end{abstract}

Keywords: tunnel boring machine; roadway supporting; constitutive model; failure criterion; numerical simulation; in-situ monitoring

\section{Introduction}

In China, coal is the major energy source and it accounts for about $68 \%$ of the total primary energy consumption. As the coal resources within shallow grounds are depleting, mining operation have been moving to increasing deep grounds in recent years [1]. In China, the average depth of coal mining operations has reached up to $556 \mathrm{~m}$ and it is increasing at a rate of 8 to $12 \mathrm{~m}$ per year. For metal mines, the depths of mining operations are even higher. For example, the Mponeng gold mine in South Africa extends $4250 \mathrm{~m}$ below the surface [2]. As the depth of mining works increased significantly, potential risks such as the collapse of roadways surrounding rocks, high coalbed methane emissions and outbursts, as well as groundwater inrushing increased dramatically [3-6]. Consequently, 
an increasing amount of coal mines have started excavating permanent or semi-permanent roadways within rock layers rather than coal seams to obtain increased safety during mining and roadway excavation operations [6]. Compared with coal, rocks have higher strength and it is beneficial to increase the stability of roadways and reduce risks. On the other hand, the higher strength of rocks also increases the difficulties of roadway excavation and slows down the excavation speed. At present, excavation speeds in rock layers are significantly slower than these in coal seams (40 to $100 \mathrm{~m} / \mathrm{mth}$ in rock layers vs. 120 to $300 \mathrm{~m} / \mathrm{mth}$ in coal seams) [7]. Typically in mining operations, roadways in rock layers include main roadways and other auxiliary roadways for transportation, ventilation, coalbed methane drainage, and groundwater drainage roadways purposes. They should be finished before the coal seam roadways start being used for excavation. Obviously, a whole mining operation would be delayed by a low penetration rate in rock layers.

Increasing the safety and speed of coal mine roadway excavation is the key factor for safe and effective mining operations. For over one hundred years, roadways or tunnels were excavated by using drilling and blasting technology. While intensive application of explosives increases potential risks in roadway excavation, and toxic smoke also results in health hazards for miners. Since the 1960s, mechanical excavation equipment (roadheader, continue miner, etc.) were introduced in roadway excavation. The use of these machines dramatically increased safety and excavation speeds. Nevertheless, these machines are not able to break hard rocks [8]. TBMs (Tunnel Boring Machines) have a higher rock breakage capacity. Moreover, rock breakage, rock chips loading, and roadway support can be conducted simultaneously by using TBMs [9]. TBMs have been widely applied in tunneling, though application cases of TBMs in coal mines have barely been reported [10].

After excavation, roadway rock deformation or damage is encountered. Therefore, these roadways need reinforcement and support to ensure the safety of excavation works. Much research has proposed the optimization of coal mine roadway support design based on the results of numerical simulation or in-situ monitoring [11]. Based on the simulation results of FLAC3D, Wang proposed full cross-section anchor-grouting reinforcement technology and applied it in underground coal mine roadways with loose and fractured surrounding rocks based on simulation results of FLAC3D, while Cao resolved the problems of lateral wall collapse and severe floor heaving in roadway support involving fractured rock layers [12,13]. Huang proposed a concrete-filled steel tubular support structure to eliminate the problems of large-scale deformation of deep roadways [14]. Stone presented a designing methodology of roadway support based on statistical evaluation of in-situ monitoring results [15]. Yang evaluated the rock mass properties of roadways surrounding rocks by using the geological strength index (GSI) and established the numerical model for roadways using UDEC (Universal Distinct Element Code). Deformation and stress behavior of roadways under different support conditions was obtained and a "bolt-cable-mesh-shotcrete + shell" combined support mode was subsequently proposed [16]. When compared with traditional roadways or tunnels, TBM-excavated roadways have some different characteristics on surrounding rock properties (TBMs are typically used in hard rock strata), for cross section geometry (rectangular or straight wall arch cross section of traditional method vs. circular cross section of TBM method), as well as for excavation-induced stress paths (dynamic blasting loading vs. static loading of machine cutting). These differences mean te support pattern and parameters of TBM-excavated coal mine roadways still need to be settled.

This paper proposed a support design methodology for TBM-excavated roadways in deep coal mines. First of all, the very specific in-situ stress parameters were obtained by in-situ measurement. Secondly, an innovative rock constitutive model which takes anisotropic damage and failure into consideration was established, and a non-linear failure criterion obtained from previous laboratory rock tests rather than conventional universal linear failure criteria was also used to further enhance calculation precision. Thirdly, a proposed constitutive model and failure criterion were introduced into computer simulation software by using new DLL (dynamic link library) files of simulation software and roadway support design was made based on simulation results. Finally, the in-situ monitoring of TBM-excavated roadway was implemented in Zhanji coal mine, Huainan, China and the proposed 
support design was verified by monitoring data [17-19]. The study results indicated that the roadway surrounding rocks remained stable after excavation and roadway supporting, and the supporting design is able to fulfill requirements of ensuring roadway stability and enhancing the efficiency of supporting roadways.

\section{Engineering Background}

Zhangji coal mine is a large scale underground colliery located at Huainan, Anhui province, China (shown in Figure 1a) with an annual output capacity of 13 million tons of raw coal. The working horizontal extends from $-450 \mathrm{~m}$ to $-1000 \mathrm{~m}$. Zhangji coal mine covers seven mining areas which are the East-I, East-II, East-III, West-I, West-II, West-III, and North-I mining areas. The primary minable coal seams within Zhangji coal mine include No. 13-1, No. 11-2, No. 8, No. 6, as well as No. 1 and the total thickness of coal seams is $21.08 \mathrm{~m}$. The measured resources and minable reserves of Zhangji coal mine are 17.78 billion and 8.77 billion tons of raw coal, respectively [20].

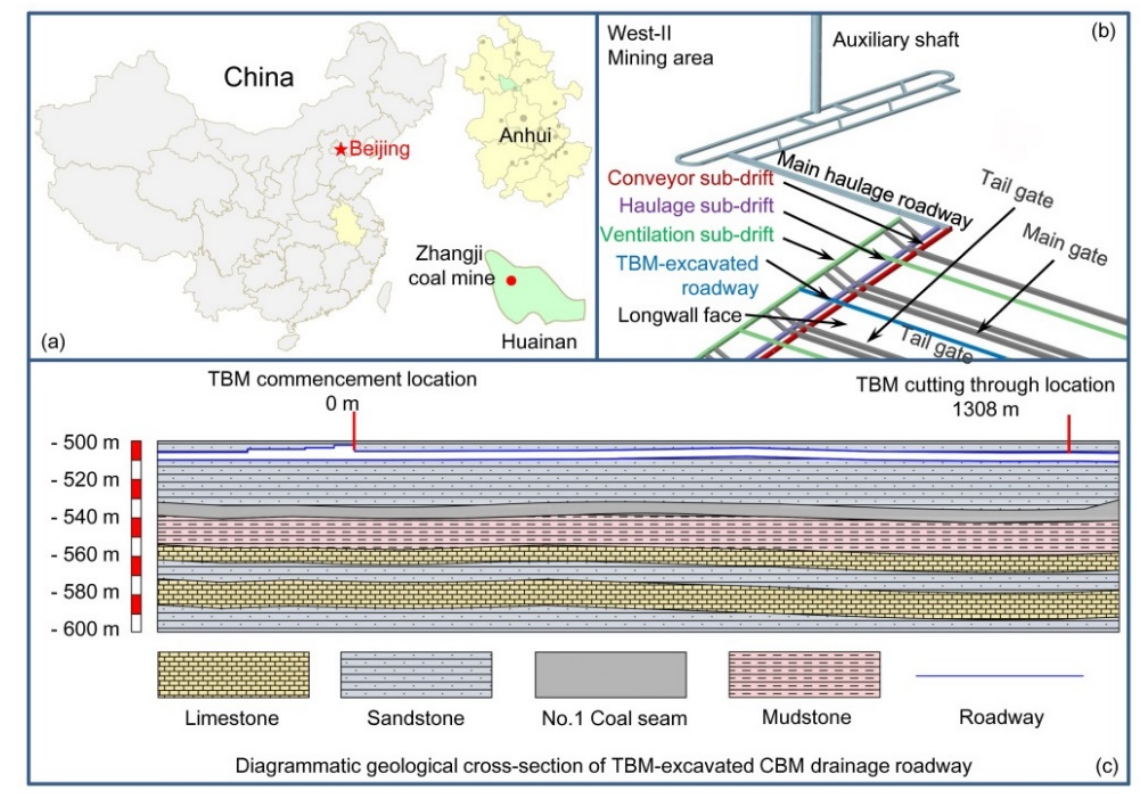

Figure 1. Simplified map of Zhangii coal mine and layout of a Tunnel Boring Machine (TBM)-excavated coalbed methane (CBM) drainage roadway. (a): location of Zhangji coal mine (b): position of TBM-excavated roadway (c): geological sketch of TBM-excavated roadway.

The West-II mining area is situated in west wing of Zhangji coal mine with the No.1 coal seam as its primary minable coal seam, and the mining operations within the West-II mining area are conducted from $-480 \mathrm{~m}$ to $-625 \mathrm{~m}$. The No.1 coal seam has an average thickness of $6.5 \mathrm{~m}$, a dip angle of $3^{\circ}$ to $5^{\circ}$, and a calorific value of $6000 \mathrm{kcal} / \mathrm{kg}$. The coal is classified as high volatile bituminous coal and coking coal and the thickness of overburden is about $500 \mathrm{~m}$. The coal seam gases (mainly include $\mathrm{CH}_{4}$, $\mathrm{CO}, \mathrm{H}_{2} \mathrm{~S}, \mathrm{CO}_{2}$, etc.) content of the $\mathrm{No} .1$ coal seam is 8.05 to $11.22 \mathrm{~m}^{3} / \mathrm{t}$ and the gas pressure of coalbed methane (CBM) ranges from 1.4 to $4.35 \mathrm{MPa}$. Generally, gas content greater over $8 \mathrm{~m}^{3} / \mathrm{t}$ or a gas pressure greater than $0.74 \mathrm{MPa}$ is considered sufficient to initiate an outburst if other conditions are favorable. Therefore, the No.1 coal seam is considered to be an outburst-prone coal seam. In order to eliminate coal and gas outburst risk, CBM drainage roadways were excavated prior to coal mining operations.

\subsection{Description of Working Site}

The TBM-excavated roadway is the overlying CBM drainage roadway of 1413A longwall panel in Zhangji coal mine, China (Figure 1b). The roadway has a length of $1598 \mathrm{~m}$, a diameter of $4.5 \mathrm{~m}$, and a buried depth of $505 \mathrm{~m}$ (shown in Figure 1c). In total, $1308 \mathrm{~m}$ section of the roadway was excavated 
by a gripper TBM, which was located in the West-II panel north mining area. The objective of the roadway is conducting CBM drainage works, thereby eliminating the potential risk of explosion and gases outburst when the longwall is retreating [21].

The overlying CBM drainage roadway was excavated $25 \mathrm{~m}$ above the No.1 coal seam, and the horizontal distance from the overlying drainage roadway to main gate is $30 \mathrm{~m}$. Before the excavation of the main gate and tail gate, the overlying drainage roadway was constructed, and downcast boreholes were drilled from overlying drainage roadway to the coal seam in order to reduce pre-drainage and eliminate outburst risks in roadway excavation works. After coal extraction works started, the longwall face advanced forward, the coal roof collapsed, and fractures generated between the coal seam and the No.1 overlying drainage roadway, meaning the CBM could be extracted from the No.1 overlying drainage roadway. The overlying CBM drainage roadway lies on the roof of the coal seam with a length of $1500 \mathrm{~m}$, and the geometry of the overlying drainage roadway is a circle with a diameter of $4.5 \mathrm{~m}$. Taking the reduction of construction cost and the improvement of efficiency of roadway support works into account, the TBM-excavated roadway was supported by rock bolts instead of the segments that were typically used in TBM-excavated tunnels [22].

\subsection{Rock Property}

Geological settings have been studied through a series of measurements and surveying. Coal measure strata lie in the Shanxi formation of Permian and Taiyuan formation of Carboniferous, which consists of coal, medium sandstone, fine sandstone, siltstone, and argillaceous sandstone (shown in Figure 1).

Along the roadway alignment, the strata consist of medium sandstone, fine sandstone and siltstone, and the UCS (uniaxial compressive strength) which varies between 41.6 and $105.7 \mathrm{MPa}$. The roadway was excavated through solid sandstone strata.

The roadway is located in a 27-m-thick sandstone strata and No.1 coal seam is 25 to $30 \mathrm{~m}$ beneath the roadway. The overburden of roadways consists of clay layers, sand layers, mudstone, and sandstone strata. The total overburden thickness is 480 to $500 \mathrm{~m}$ (shown in Figure 1).

\subsection{In-Situ Stress Field}

In-situ stress is a principal element which causes rock deformation and failure, and its magnitude and orientation significantly affect the stability of roadways [23,24]. In order to investigate the in-situ stress of Zhangji coal mine, borehole stress relief measurements were conducted in the mine's roadways by Anhui University of Science and Technology. The measurement results suggest that the in-situ stress field is controlled by tectonic stress. The stress filed parameters had been obtained through analysis: Vertical stress is approximately $14.3 \mathrm{MPa}$ and is related to a overburden of approximately $500 \mathrm{~m}$. The maximum horizontal stress is $21.6 \mathrm{MPa}$ and oriented $130.72^{\circ}$, and the minimum horizontal stress is $13.2 \mathrm{MPa}$ and oriented $223.55^{\circ}$. The stress field surveying results are shown in Table 1.

Table 1. Parameters of in-situ stress field.

\begin{tabular}{cccc}
\hline Stress Components & $\boldsymbol{\sigma}_{1}{ }^{1}$ & $\boldsymbol{\sigma}_{3}{ }^{2}$ & $\boldsymbol{\sigma}_{\boldsymbol{v}}{ }^{3}$ \\
\hline Magnitude $(\mathrm{MPa})$ & 21.6 & 13.2 & 14.3 \\
Orientation $\left(^{\circ}\right)$ & 130.72 & 223.55 & \\
\hline 1 maximum & &
\end{tabular}

${ }^{1}$ maximum horizontal stress; ${ }^{2}$ minimum horizontal stress; ${ }^{3}$ vertical stress.

\section{A Constitutive Model and Failure Criterion of Surrounding Rocks under TBM Excavation}

A constitutive model and failure criterion play a indispensable role in studying stress, strain, and failure distribution behaviors of roadways surrounding rocks. The constitutive model defines the stress-strain relationship of rock materials and a failure criterion is developed to predict the 
failure of rock materials. The constitutive model and failure criterion should be able to reproduce material behavior, stress condition, as well as loading and unloading paths $[25,26]$. Therefore, universal constitutive models and failure criteria cannot fit all mechanical behaviors of rocks or rock-like materials. In previous research, universal constitutive models and failure criteria such as Mohr-Coulomb model and failure criterion were widely used. The mechanical performance of rock materials is influenced by both rock lithological characters and stress paths. Even for the same rock material, the difference in loading or unloading patterns results in varying mechanical properties for rocks. Universal constitutive models ignore these influences, meaning applications of these universal constitutive models and failure criteria results in large modeling errors, especially under complex loading conditions or stress paths because most universal constitutive models and failure criteria are established based on simple uniaxial loading tests [27]. In this paper, damage factors along the maximum and minimum principle stresses were added into consideration and a constitutive model considering anisotropic damage was proposed. The failure criterion of the surrounding rocks was obtained from rock mechanical tests. In subsequent research works, the proposed constitutive model and failure criterion will be introduced into computer simulation software.

\subsection{Constitutive Model}

Previous constitutive models barely take the microscopic damage of rock materials into consideration. Few constitutive models use a single damage factor or damage coefficient to define the influences of microscopic damage on the mechanical behaviors of rocks. In loading and unloading processes, the microscopic damage development behaviors are different along the maximum and minimum principle stress directions. In this research, an anisotropic tensor and damage tensor were introduced into the constitutive model for representing anisotropy and damage factors along the maximum and minimum principle stress direction. Based on lab test results and working experiences from working sites, hard rocks barely show plastic behaviors and macrocosmic damage happens suddenly. The stress-strain relationship is mainly affected by the generation and development of microcosmic damage and failure. The model was established based on an elastic model. After adding damage factors along maximum and minimum principle stresses directions, as well as some anisotropic parameters, the constitutive model was able to represent influences of damage on the stress-strain relationship. In the proposed constitutive model, microscopic damage along the maximum and minimum principle stress directions was indicated by two damage factors. Therefore, the anisotropic properties (different damage development behaviors along the maximum and minimum principle stress directions) of brittle rocks are able to be represented by the proposed constitutive model. The proposed constitutive model was subsequently applied in computer simulations by rebuilding the constitutive model and failure criterion files using the simulation software.

First of all, if rock is regarded as an isotropic material, then the stress-strain relationship can be expressed as:

$$
\sigma_{i j}=C_{i j r s} \varepsilon_{r s}
$$

where $\sigma_{i j}$ is the component of the Cauchy stress tensor, $\varepsilon_{r s}$ means the component of the stain tensor, and $C_{i j r s}$ indicates the component of the elastic stiffness tensor.

$$
C_{i j k l}=\lambda^{e} \delta_{i j} \delta_{k l}+\mu^{e}\left(\delta_{i k} \delta_{j l}+\delta_{i l} \delta_{j k}\right)
$$

where $\lambda^{e}$ and $\mu^{e}$ are Lamé's first parameter and Lamé's second parameter, and $\delta$ represents the Kronecker delta.

Effective stress $\widetilde{\sigma}$ can be expressed as:

$$
\widetilde{\sigma}=(\boldsymbol{I}-\boldsymbol{D})^{-1} \sigma=\boldsymbol{M}(\boldsymbol{D}) \sigma
$$




$$
\boldsymbol{M}(\boldsymbol{D})=\left[\begin{array}{ccc}
\frac{1}{1-D_{1}} & 0 & 0 \\
0 & \frac{1}{1-D_{2}} & 0 \\
0 & 0 & \frac{1}{1-D_{3}}
\end{array}\right]
$$

where, $\boldsymbol{D}$ is damage tensor, $D_{1}, D_{2}$, and $D_{3}$ are components of the damage tensor on coordinate directions, and $I$ is the unit tensor.

An effective compliance tensor can be expressed as an inversed effective stiffness tensor:

$$
\begin{gathered}
\widetilde{S}=\widetilde{C}^{-1}=C^{-1} M(D) \\
\varepsilon^{e}=C^{-1} \widetilde{\sigma}=C^{-1} M(D) \sigma=C^{-1}(I-D)^{-1} \sigma
\end{gathered}
$$

where $\widetilde{S}$ is an effective compliance tensor, $\varepsilon^{e}$ is the elastic strain, $C$ indicates the stiffness tensor of undamaged rocks, and $\widetilde{C}$ means the stiffness tensor of rocks.

For coordinate directions:

$$
\left\{\begin{array}{l}
\varepsilon_{1}^{e} \\
\varepsilon_{2}^{e} \\
\varepsilon_{3}^{e}
\end{array}\right\}=\frac{1}{E}\left[\begin{array}{ccc}
\frac{1}{1-D_{1}} & \frac{-v}{1-D_{2}} & \frac{-v}{1-D_{3}} \\
\frac{-v}{1-D_{1}} & \frac{1}{1-D_{2}} & \frac{-v}{1-D_{3}} \\
\frac{-v}{1-D_{1}} & \frac{-v}{1-D_{2}} & \frac{1}{1-D_{3}}
\end{array}\right]\left\{\begin{array}{c}
\sigma_{1} \\
\sigma_{2} \\
\sigma_{3}
\end{array}\right\}
$$

where, $\varepsilon_{1}^{e}, \varepsilon_{2}^{e}$, and $\varepsilon_{3}^{e}$ are strain components on coordinate directions, $\sigma_{1}, \sigma_{2}$, and $\sigma_{3}$ are stress components on coordinate directions, $v$ is the Poisson's ratio, and $E$ is an elastic module.

Based on the hypothesis of elastic energy equivalence, we get:

$$
\widetilde{\boldsymbol{C}}^{-1}(\boldsymbol{D})=(\boldsymbol{I}-\boldsymbol{D})^{T} \boldsymbol{C}^{-1}(\boldsymbol{I}-\boldsymbol{D})
$$

where $\boldsymbol{D}$ is fourth order asymmetric damage tensor.

$$
\boldsymbol{D}=\left[\begin{array}{cccccc}
D_{1} & 0 & 0 & 0 & 0 & 0 \\
\frac{v}{1-v} D_{1} & 0 & 0 & 0 & 0 & 0 \\
\frac{v}{1-v} D_{1} & 0 & 0 & 0 & 0 & 0 \\
0 & 0 & 0 & 0 & 0 & 0 \\
0 & 0 & 0 & 0 & D_{3} & 0 \\
0 & 0 & 0 & 0 & 0 & D_{3}
\end{array}\right]
$$

Then the relationship of effective stress components and stress components can be expressed as:

$$
\left\{\begin{array}{c}
\widetilde{\sigma}_{11} \\
\widetilde{\sigma}_{22} \\
\widetilde{\sigma}_{33} \\
\widetilde{\sigma}_{23} \\
\widetilde{\sigma}_{13} \\
\widetilde{\sigma}_{12}
\end{array}\right\}=\left[\begin{array}{cccccc}
\frac{D_{1}}{1-D_{1}} & 0 & 0 & 0 & 0 & 0 \\
\frac{v}{1-v} \frac{D_{1}}{1-D_{1}} & 1 & 0 & 0 & 0 & 0 \\
\frac{v}{1-v} \frac{D_{1}}{1-D_{1}} & 0 & 1 & 0 & 0 & 0 \\
0 & 0 & 0 & 1 & 0 & 0 \\
0 & 0 & 0 & 0 & \frac{1}{1-D_{3}} & 0 \\
0 & 0 & 0 & 0 & 0 & \frac{1}{1-D_{3}}
\end{array}\right]\left\{\begin{array}{c}
\sigma_{11} \\
\sigma_{22} \\
\sigma_{33} \\
\sigma_{23} \\
\sigma_{13} \\
\sigma_{12}
\end{array}\right\}
$$

$\Gamma$ can then be set as anisotropic tensor:

$$
\boldsymbol{\Gamma}=\left[\begin{array}{cccccc}
1 & 0 & 0 & 0 & 0 & 0 \\
\frac{v}{1-v} & 0 & 0 & 0 & 0 & 0 \\
\frac{v}{1-v} & 0 & 0 & 0 & 0 & 0 \\
0 & 0 & 0 & 0 & 0 & 0 \\
0 & 0 & 0 & 0 & \xi & 0 \\
0 & 0 & 0 & 0 & 0 & \xi
\end{array}\right]
$$


The degree of anisotropy can be expressed as:

$$
\boldsymbol{Q}=(1-\gamma) \boldsymbol{\Gamma}+\gamma \boldsymbol{I}
$$

where $\gamma$ is the anisotropic coefficient: when $\gamma=0$, the damage of rock is fully anisotropic, while if $\gamma=1$, the damage of rock will be fully isotropic. $Q$ is the fourth order tensor used to represent the degree of anisotropy, $\Gamma$ is the anisotropic tensor, and $\xi$ is the material coefficient.

Under asymmetrical loading, the damage tensor is:

$$
\boldsymbol{D}=\boldsymbol{Q} \cdot D_{1}+\boldsymbol{R} \boldsymbol{R} Q \boldsymbol{R}^{T} \boldsymbol{R}^{T} D_{3}
$$

where $D_{1}$ is the damage factor along the maximum principle stress direction, $D_{3}$ is the damage factor along the minimum principle stress direction, and $R$ is the rotation tensor.

The constitutive model of rocks considering anisotropic damage can be expressed by Equation (14).

$$
\sigma=\widetilde{C} \varepsilon=(\boldsymbol{I}-\boldsymbol{D}) \boldsymbol{C} \varepsilon
$$

where $\sigma$ indicates stress and $\varepsilon$ represents strain.

\subsection{Non-Linear Failure Criterion}

The Mohr-Coulomb criterion is a universal criterion which can be used for all types of rocks and it usually is treated as a failure criterion for brittle rocks. Although the Mohr-Coulomb criterion had been widely applied since the early 1900s and continues to be used at present, it still has some limitations [28]. One of the most significant limitations is the failure envelope of the Mohr-Coulomb criterion. The conventional failure envelope of the Mohr-Coulomb criterion is typically considered as a straight line, which means the cohesion $\mathrm{c}$ and friction angle $\phi$ of the rock are treated as constant values. Some scholars found that the cohesion and friction angle of rocks are not constant. With the formation and development of micro-cracks, the initial cohesion is lost and reaches its final value. Moreover, generation of a micro-shear plane also results in changing of frictional strength [29,30]. Consequently, the linear strength envelope usually is not able to present the rock failure behaviors from the excavation site. Applying improper failure criterion in calculations will result in large modeling errors.

Tang conducted triaxial cyclic loading-unloading tests of rock specimens which are sampled from excavation working sites [31]. The rock specimens are loaded and unloaded cyclically until rock specimens damage occurs when reproducing and simulating the stress path of TBM excavation. The tests were conducted under four different confining pressure levels $(10,15,25$, and $30 \mathrm{MPa})$ due to the ground pressure ranges for 15 to $30 \mathrm{MPa}$ in deep-buried coal mine roadways. The initial axial force in four tests was set to be higher than uniaxial compressive strength and lower than triaxial compressive strength under four different confining pressures $(250,320,380$, and $390 \mathrm{kN})$. Because the cutter head of TBM applies thrust forces on rock faces circularly during excavation processes, the processes of rock breakage and excavation essentially are cyclic loading-unloading processes of rocks. Therefore, the initial confine pressures were reduced from initial levels $(10,15,25$, and $30 \mathrm{MPa})$ to zero with unloading speed of $0.05 \mathrm{MPa} / \mathrm{s}$. If no damage occurred on rock specimens after unloading, the confine pressure is added to the initial level and the axial force is set to be $20 \mathrm{kN}$ higher. The loading-unloading processes were repeated until rock specimens were damaged.

The strength envelopes are supposed to be common tangents of adjacent circles according to Mohr's Theory. Various slope angles of different common tangents between adjacent circles indicated that the single linear strength envelope are not capable of representing strength behavior under all confined pressure conditions. The strength envelope must be a curve and the function of this curved strength envelope is the failure criterion of rock material, namely the criterion of macrocosmic damage or failure of rocks. Various curves were used to fit the Mohr circles and finally the power function curve was chosen as the strength envelope due to its highest value of determination coefficients $\left(R^{2}\right)$. 
A strength envelope was fitted based on test results and Mohr circles (shown in Figure 2), and the function of the non-linear strength envelope is shown in Equation 15:

$$
\tau=6.946 \sigma^{0.77}+23.72
$$

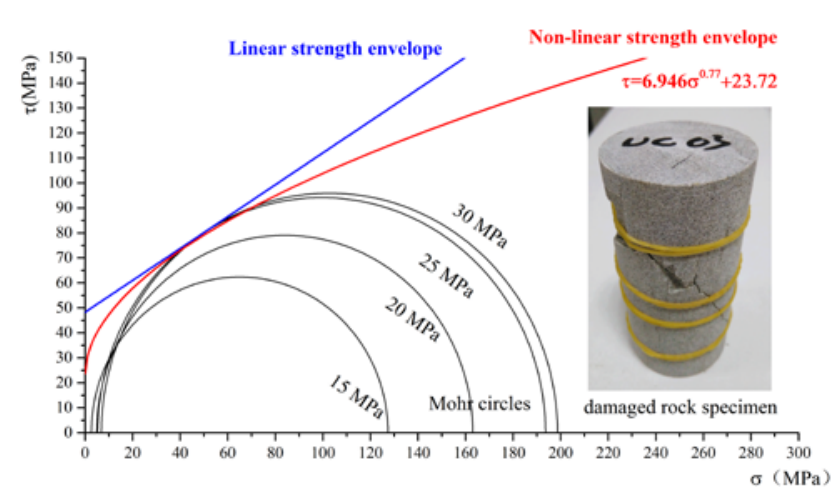

Figure 2. Strength envelopes of Mohr circles.

The determination coefficients $\left(\mathrm{R}^{2}\right)$ of proposed non-linear failure criterion and conventional linear failure criterion are 0.989 and 0.911 , respectively. It can be seen from Figure 2 that the strength envelope of proposed non-linear failure criterion has a much better performance on fitting Mohr circles than that of conventional linear failure criterion.

\section{Numerical Simulation}

The model used in this study was established by Fast Lagrangian Analysis of Continua (FLAC). A huge amount of research on coal mine roadway support and surrounding rock stability has indicated that the mechanisms of surrounding rock failure after excavations can be extremely complex [24,32]. The successful application of computer simulations therefore requires a set of detailed parameters of rock properties and in-situ stress fields. Moreover, the constitutive model and failure criterion of surrounding rocks under very specific stress conditions and stress paths should be studied to ensure the precision of simulation results. In-situ stress and rock property parameters have been obtained by in-situ measurement and laboratory testing. Proposed constitutive models and failure criterion have been introduced in FLAC3D simulation software by using an alternative DLL (dynamic link library) files. The Numerical implementation processes are shown in Figure 3. 


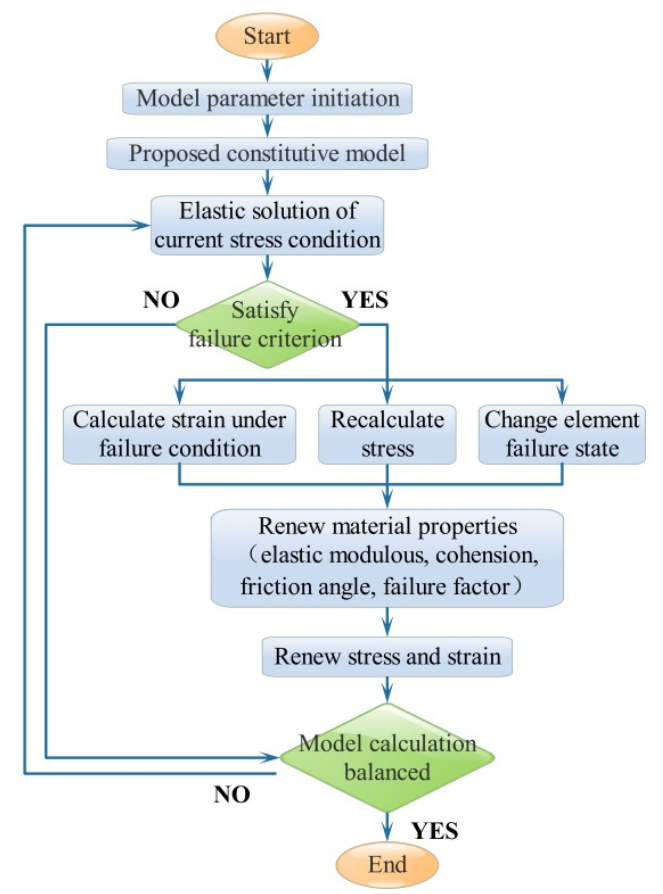

Figure 3. Numerical implementation processes of proposed constitutive model and failure criterion.

\subsection{Model Calibration}

The rock specimens for laboratory tests were obtained from a TBM excavation working site. Triaxial compression tests were conducted in order to obtain rock property parameters and the stress-strain relationship. The triaixal tests were also simulated using software and the test results of computational simulation were compared with these of lab tests for verifying the feasibility of the proposed constitutive model and failure criterion.

The results of lab tests and computational simulation are illustrated in Table 2, where $\sigma_{1}$ indicates the axial stress when there is rock specimen damage, $\sigma_{3}$ represents confinement pressure, $\varepsilon_{1}$ denotes the axial strain, and $\varepsilon_{3}$ means the lateral strain. The simulation results suggested that the deviation between lab tests and simulations is negligible. The constitutive model, failure criterion, and material parameters are able to represent the mechanical behaviors of rock specimens in lab tests.

Table 2. Model calibration results.

\begin{tabular}{cccccc}
\hline \multirow{2}{*}{$\boldsymbol{\sigma}_{1}(\mathbf{M P a})$} & \multirow{2}{*}{$\boldsymbol{\sigma}_{3}(\mathbf{M P a})$} & \multicolumn{2}{c}{$\varepsilon_{1}$} & \multicolumn{2}{c}{$\varepsilon_{3}$} \\
\cline { 3 - 6 } & & Simulation & Lab Tests & Simulation & Lab Tests \\
\hline 127.39 & 15 & 0.0169 & 0.0151 & 0.0048 & 0.0042 \\
163.06 & 20 & 0.0171 & 0.0154 & 0.0052 & 0.0062 \\
193.63 & 25 & 0.0175 & 0.0155 & 0.0045 & 0.0037 \\
198.72 & 30 & 0.0193 & 0.0189 & 0.0043 & 0.000028 \\
\hline
\end{tabular}

\subsection{Finite Difference Model}

The sizes of numerical models were decided based on the Saint Venant principle. According to the Saint Venant principle and construction experience, the stress redistribution, surrounding rock deformation, and other effects of excavation out of a domain with 3 to 5 times the roadway radius are negligibly small [33]. The diameter of the roadway is $4.53 \mathrm{~m}$, therefore the model size is taken as $60 \mathrm{~m} \times 120 \mathrm{~m} \times 60 \mathrm{~m}(\mathrm{X}, \mathrm{Y}, \mathrm{Z}$ axis direction). Stress and displacement distribution of the roadway surrounding rocks out of the model range can be considered as being barely influenced by roadway excavation. The model consists of 40,000 elements and 41,041 grid points, while the excavation part 
was modeled using cylinder elements with six grid points and the surrounding rock was modeled using radcylinder elements and eight grid points. The benefit of modeling surrounding the rock using radcylinder elements is that elements and grid points are intensive in surrounding areas of the roadway and are extensive in the areas far from the roadway. This significantly reduces the computation, thereby ensuring precision of simulation in near-roadway areas. The model geometry is shown in Figure 4. Prior to numerical simulation, the obtained power function failure criterion was introduced with the software by rewriting a build-in constitutive model for the simulation software.

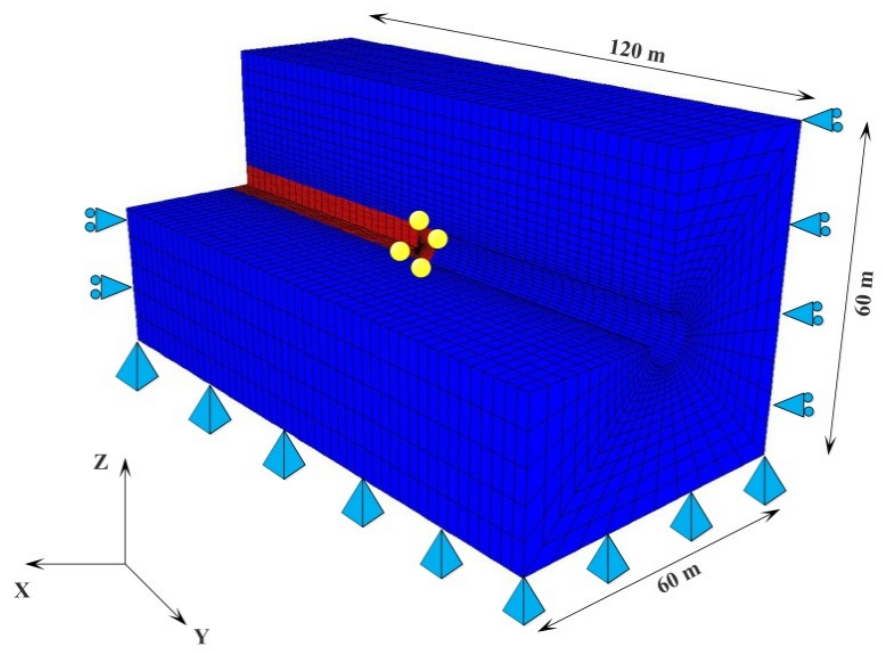

Figure 4. Computational model: Roadway, excavation section (red region), and monitoring points (golden spots).

In this model, rock parameters were gained from the previous rock mechanical tests. Model element lengths were set as $1.0 \mathrm{~m}$ along the longitudinal direction of the roadway. As the rock mechanical properties within the model range are similar, the model was considered as being homogeneous for getting higher computational efficiency with acceptable error rates. The details of rock properties are provided in Table 3.

Table 3. Rock properties.

\begin{tabular}{ccccccc}
\hline $\begin{array}{c}\text { Density } \\
\left(\mathbf{k g} / \mathbf{m}^{3}\right)\end{array}$ & $\begin{array}{c}\text { Elastic } \\
\text { Modulus } \\
\left(\mathbf{1 0 ^ { 4 }} \mathbf{M P a}\right)\end{array}$ & $\begin{array}{c}\text { Bulk } \\
\text { Modulus } \\
\left(\mathbf{1 0}^{\mathbf{4}} \mathbf{M P a}\right)\end{array}$ & $\begin{array}{c}\text { Shear } \\
\text { Modulus } \\
\left(\mathbf{1 0}^{\mathbf{4}} \mathbf{M P a}\right)\end{array}$ & $\begin{array}{c}\text { Passion } \\
\text { Ratio }\end{array}$ & $\begin{array}{c}\text { Cohesion } \\
\mathbf{( M P a})\end{array}$ & $\begin{array}{c}\text { Friction } \\
\left.\text { Angle } \mathbf{(}^{\circ}\right)\end{array}$ \\
\hline 2500 & 4.5 & 2.5 & 1.875 & 0.20 & 9.0 & 45 \\
\hline
\end{tabular}

Rock bolts were modeled using cable elements. The rock bolt parameters input are shown in Table 4. Three different support patterns (unsupported, roof support, and roof-sides support) are applied in the model. The stress field redistribution and displacement of surrounding rock under three support conditions were simulated and analyzed and the most feasible support layout can be decided based on simulation results. Support layouts are shown in Figure 5. In engineering practices, the TBM is equipped with two rock bolters that have moving and rotating functions. The rock bolters drill boreholes on surrounding rocks and rock bolts are fixed in the boreholes by resin cartridges. The tunnel excavation and rock bolt installation works are conducted simultaneously. 
Table 4. Rockbolt mechanical properties.

\begin{tabular}{ccccccc}
\hline $\begin{array}{c}\text { Diameter } \\
(\mathbf{m m})\end{array}$ & $\begin{array}{c}\text { Length } \\
(\mathbf{m m})\end{array}$ & $\begin{array}{c}\text { Elastic } \\
\text { Modulus } \\
\left(\mathbf{1 0 ^ { 4 }} \mathbf{M P a}\right)\end{array}$ & $\begin{array}{c}\text { Tensile } \\
\text { Strength } \\
\mathbf{( M P a )}\end{array}$ & $\begin{array}{c}\text { Passion } \\
\text { Ratio }\end{array}$ & $\begin{array}{c}\text { Rigidity of } \\
\text { Resin } \\
\mathbf{( k N / m )}\end{array}$ & $\begin{array}{c}\text { Friction } \\
\text { Angle of } \\
\left.\text { Resin } \mathbf{(}^{\circ}\right)\end{array}$ \\
\hline 20 & 2000 & 20.6 & 345 & 0.30 & 1000 & 54 \\
\hline
\end{tabular}

(a)

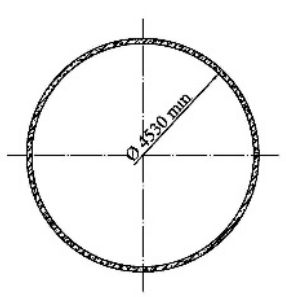

(b)

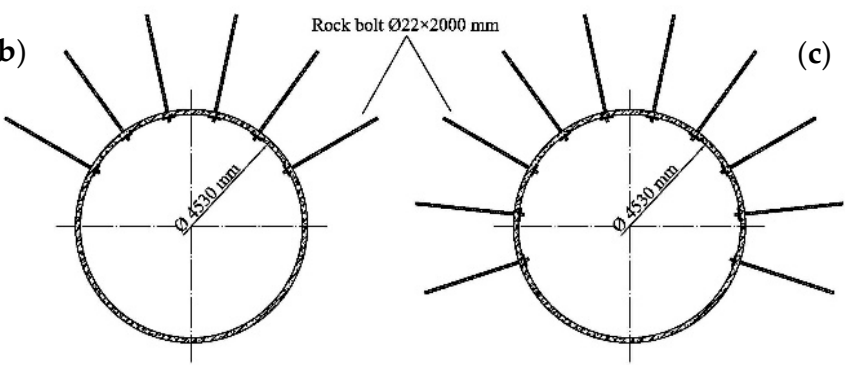

Figure 5. Three support patterns: (a) Pattern 1, unsupported; (b) Pattern 2, Roof support; (c) Pattern 3, roof-sides support.

\subsection{Simulation Procedure}

The $\mathrm{Y}$-axis in Figure 6 is the excavation direction, with excavation starting from $+\mathrm{Y}$ and moving towards the $-\mathrm{Y}$ direction. The simulation procedure is:

1. Setup the initial boundary conditions and the initial stress conditions. The in-situ stress filed parameters had been obtained through instrument works, while the maximum and minimum stress components are not perpendicular to the roadway alignment. While in FLAC3D software, stress boundary conditions are only able to be set by applying stresses that are normal to model boundaries. Therefore, for easier boundary conditions setting, both the maximum and minimum stresses need to be decomposed into two components: being parallel and perpendicular to the roadway alignment direction. As shown in Table 5, $\sigma_{1}$ and $\sigma_{3}$ indicates measured in-situ principle stresses, $\sigma_{\mathrm{x}}$ and $\sigma_{\mathrm{y}}$ means stress applied on model boundaries. Four lateral sides and the bottom of the model were fixed by roller supports and pinned supports, respectively. Then stresses were applied on six boundaries of the model based on stress decomposition results. The horizontal in-situ stress had been decomposed along the alignment of the roadway in the model. The orientation of the roadway is $32^{\circ}$, and the stress decomposition results are shown in Figure 6 and Table 5. The magnitude of stresses which are applied on the top and bottom, front and back, and lateral boundaries of the model are 14.3 $\mathrm{MPa}, 12.71 \mathrm{MPa}$ and $23.91 \mathrm{MPa}$, respectively. Figure 6 illustrates the relationship between the roadway orientation, in-situ tectonic stresses, stress applied on model boundaries, and coordinate axes of the numerical model. Black and green lines indicate roadway alignment and coordinate axes of the numerical model. Blue and red arrows represent in-situ tectonic principle stresses, and stresses applied on model boundaries. Radial lengths of arrows indicate the magnitudes of stresses. Moreover, 0, 90, 180, and 270 degree orientations indicate geodetic north, east, south, and west directions, respectively.

2. The roadway was set in the middle of the model was $30 \mathrm{~m}$ away from the model boundary to eliminate the boundary effect. Excavate a $1.0 \mathrm{~m}$ section along the excavation direction of the roadway by setting the excavation region as a null model (A null model can be assigned to zones to represent material that is removed or excavated).

3. Set a cable element in a new excavation region representing rock bolts after excavation (this step was not conducted in support pattern 1 ).

4. Record the stress and displacement on all monitor points for analysis. Monitoring points are set on the surface of roadway and in surrounding rock.

5. Repeat step 2 to step 4 until the excavation work is finished. 
Table 5. Stress decomposition results.

\begin{tabular}{cccccc}
\hline & In-Situ Stress & & \multicolumn{2}{c}{ Stress Applied on the Model } \\
\hline $\begin{array}{c}\text { Stress } \\
\text { Components }\end{array}$ & $\begin{array}{c}\text { Magnitude } \\
\mathbf{( M P a )}\end{array}$ & $\begin{array}{c}\text { Orientation of } \\
\text { Stresses }\left({ }^{\circ}\right)\end{array}$ & $\begin{array}{c}\text { Stress } \\
\text { Components }\end{array}$ & $\begin{array}{c}\text { Magnitude } \\
\mathbf{( M P a )}\end{array}$ & Orientation $\left(^{\circ}\right)$ \\
\hline$\sigma_{1}$ & 21.6 & 130.72 & $\sigma_{\mathrm{x}}$ & 23.91 & 122 \\
$\sigma_{3}$ & 13.2 & 223.55 & $\sigma_{\mathrm{y}}$ & 12.71 & 32 \\
$\sigma_{\mathrm{v}}$ & 14.3 & - & $\sigma_{\mathrm{z}}$ & 14.3 & - \\
\hline
\end{tabular}

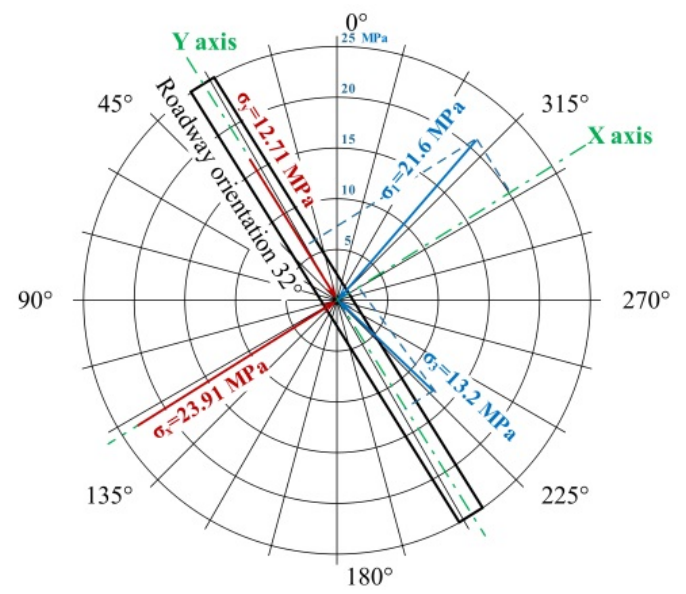

Figure 6. Decomposing tectonic stress along the roadway alignment.

All the simulation procedures had been conducted under three support conditions (unsupported, roof support, and roof-sides support), and the stress and displacement on monitor points was recorded and analyzed. The initial support design of the TBM-excavated roadway was made based on the simulation results.

\subsection{Simulation Results Analysis}

The model was launched under three conditions: no support, roof support and roof-and-ribs support. Stress redistribution, surrounding rock displacement, roadway convergence, and stress concentration under three conditions were recorded and analyzed.

\subsubsection{Stress of Surrounding Rocks}

As can be seen from Figure 7, after excavation, the stress filed of surround rock near the roadway is redistributed. The horizontal stress on the roadway roof under three support patterns (no support, roof support, and roof-sides support) are $41.33 \mathrm{MPa}, 41.35 \mathrm{MPa}$, and $40.55 \mathrm{MPa}$, respectively, the horizontal stress on the roadway floor under the three support patterns are $41.67 \mathrm{MPa}, 44.37 \mathrm{MPa}$, and $41.47 \mathrm{MPa}$, respectively, while vertical stress on roadway sides under three support patterns are 20.9 MPa, 22.3 MPa, and 24.4 MPa, respectively. The calculated stresses indicated that the horizontal stress is concentrated on the roof and floor of the roadway, and the vertical stress is concentrated on lateral sides. 


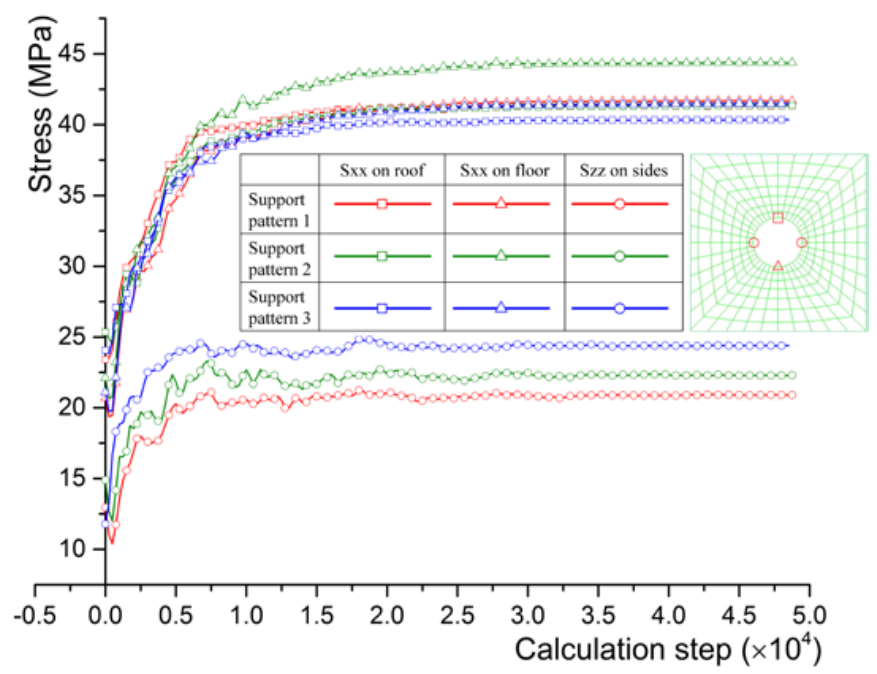

Figure 7. Stress distribution of the roadway surrounding rocks: Sxx indicates horizontal stress and Szz represents vertical stress.

\subsubsection{Displacements of Surrounding Rocks}

Figure 8 illustrates that, under the tectonic stress, the displacements on the roadway roof under three support patterns are: $4 \mathrm{~mm}, 2.2 \mathrm{~mm}$, and $2.1 \mathrm{~mm}$. The displacements on the roadway floor under three support patterns are: $2.29 \mathrm{~mm}, 2.3 \mathrm{~mm}$, and $2.5 \mathrm{~mm}$. The horizontal displacement on roadway lateral sides under three support patterns is: $7.63 \mathrm{~mm}, 7.2 \mathrm{~mm}$, and $2.01 \mathrm{~mm}$. The simulation results suggest that after rock bolt supporting, the surrounding rock of roadway deformation was controlled significantly, from $4 \mathrm{~mm}$ to about $2 \mathrm{~mm}$ on the roof and from $7.63 \mathrm{~mm}$ to around $2 \mathrm{~mm}$ on lateral sides. When the roof and lateral sides were supported and displacements on those areas were controlled, the displacement on the roadway bottom increased slightly.

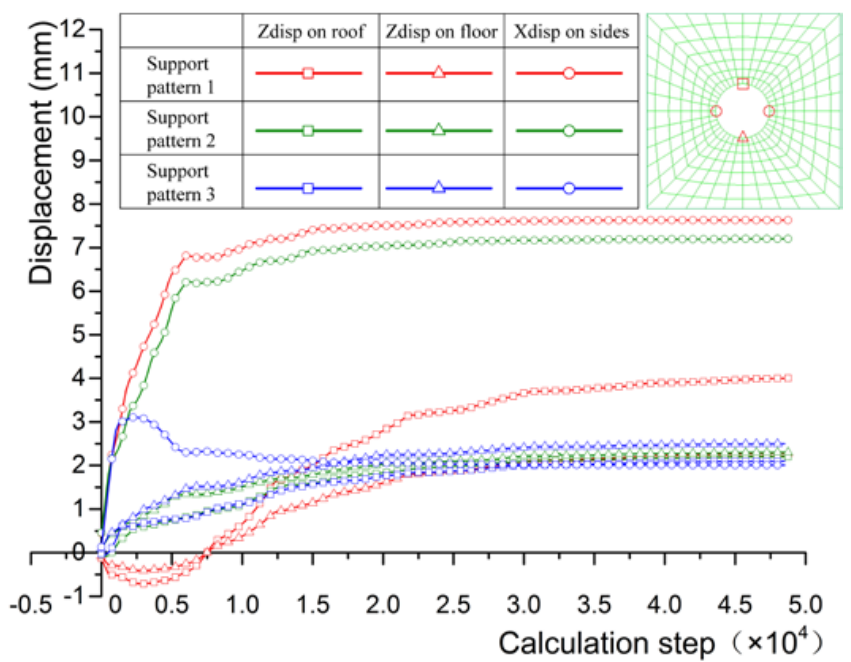

Figure 8. Displacement distribution of the roadway surrounding rocks: Xdisp indicates horizontal displacement and Zdisp represents vertical displacement.

\subsubsection{Excavation Damage Zone Distribution}

The EDZ under three support patterns are shown in Figure 9. The EDZ under support pattern 1 is approximately circular with the largest depth of $2.2 \mathrm{~m}$. In pattern 2, the range of EDZ shrinks to $0.9 \mathrm{~m}$ for the maximum due to the rock bolts support system. Meanwhile in support pattern 3 , the EDZ is distributed mainly on the rib sides and bottom of the roadway and the maximum depth is 
$0.77 \mathrm{~m}$. The EDZ range shrunk significantly after obtaining support, while there was no significant difference on the EDZ range under the roof support and roof-sides support pattern.

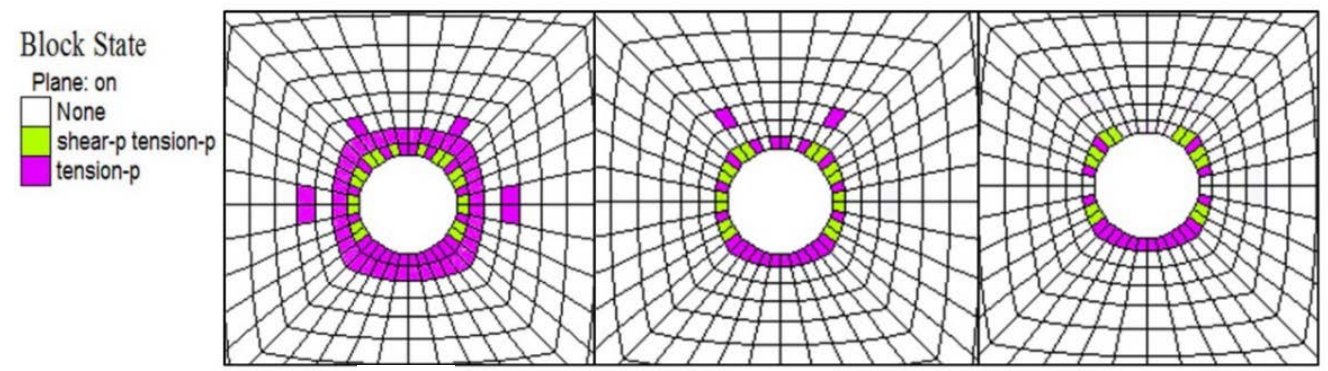

(a)

(b)

(c)

Figure 9. Excavation damage zone (EDZ) distribution under three support patterns: (a) EDZ distribution under support pattern 1; (b) EDZ distribution under support pattern 2; (c) EDZ distribution under support pattern 3.

\subsection{Decision Making of Roadway Supporting}

The initial support pattern was decided based upon the simulation results. After support, the stress redistribution changed slightly, while the roadway convergence and the range of EDZ decreased significantly. Between support patterns 1 and 2, there was no significant difference on roadway convergence and EDZ range. Compared with support pattern 2, support pattern 3 leads to a larger support range and higher safety. Support pattern 2 meets the requirement of roadway support according to simulation results and in-situ practices. Therefore, support pattern 2 which is the roof support pattern, was been chosen for the roadway supporting.

\section{In-SITU Monitoring}

In order to verify the precision of modeling simulations and study the surrounding rock deformation behavior and bolt stress, monitoring stations were set in the roadway [34]. Each station contains four rock bolt dynamometers and a set of convergence monitors. The rock bolt dynamometers were installed on the bottom of the rock bolt for monitoring the axial force of rock bolts. Roadway convergence behavior can be studied through measuring distance changing between two convergence monitor spots by laser geodimeter. The monitoring station layout is shown in Figure 10.

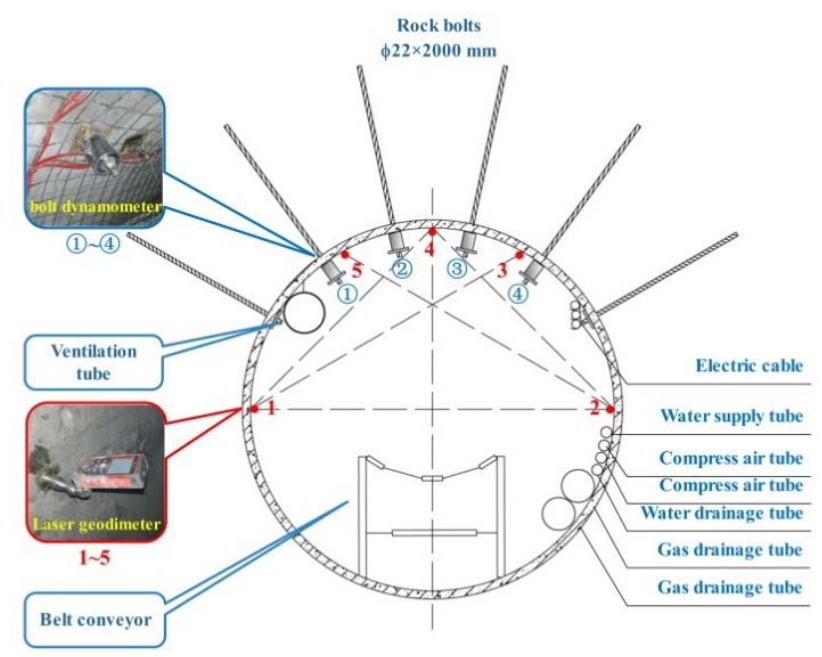

Figure 10. Monitoring station layout: 1-5 are convergence monitor spots and laser geodimeter; (1)-(4) indicate No.1 to No.4 rock bolt dynamometers. 


\subsection{Rock Bolt Axial Force Monitoring}

Figure 11 shows the monitoring results of bolt axial force. The largest bolt axial force $(62 \mathrm{kN})$ appeared on the No. 2 rock bolt 20 days after excavation. Monitoring data illustrated that after rock bolts were installed, the bolt axial force increased rapidly on the rock bolts installed near the roof of roadway in 10 days, then the increasing speed slowed down and the bolt axial force remained stable after 20 days. In contrast, the axial force of rock bolts installed near the shoulders and lateral sides of the roadway decreased rapidly in 10 days and then leveled off at around $45 \mathrm{kN}$. Monitoring data suggested that the surrounding rock reached a stable state and the support design is reasonable.

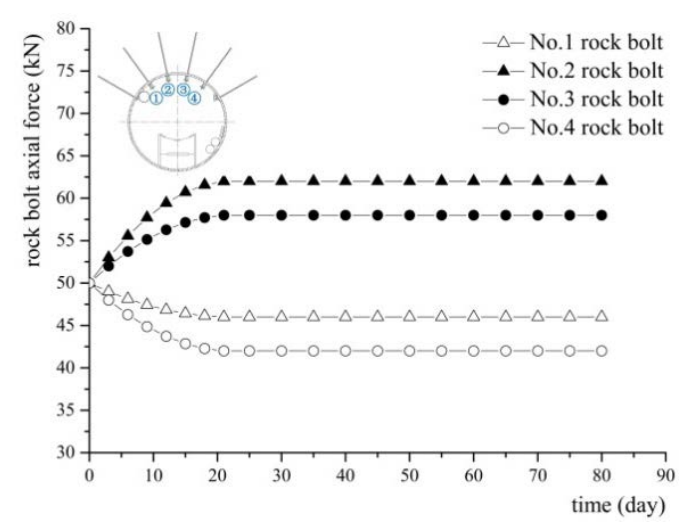

Figure 11. Monitoring results for the bolt axial force. (1)-(4) indicate No.1 to No.4 rock bolt dynamometers.

\subsection{Roadway Convergence Monitoring}

Convergence monitors were installed on the upper hemisphere of the roadway because the conveyor belt was installed on the floor. The roadway convergence is shown in Figure 12, the lateral convergence shot up to $8 \mathrm{~mm}$ within 20 days after roadway excavation, and then the increasing of convergence slowed down gradually and stabilized at $12 \mathrm{~mm}$ after 30 days. The monitoring data indicates that the surrounding rock deformation had been controlled significantly under support pattern 2 (roof support). The convergence is extremely small when considering that the roadway width is $4.53 \mathrm{~m}$.

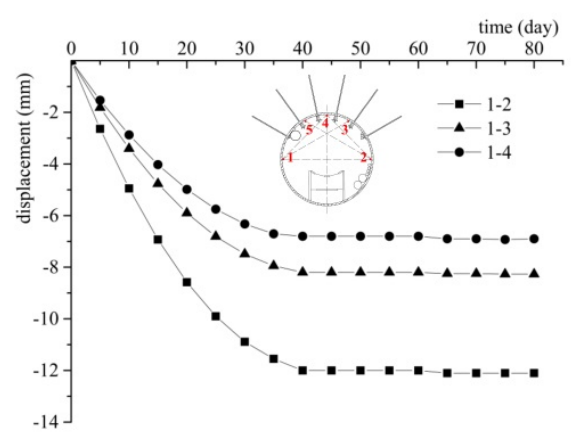

Figure 12. Monitoring results of roadway convergence. Red numbers 1-5 represent convergence monitor spots.

\section{Conclusions}

This paper presents a case study on optimization of the support design of a TBM-excavated roadway. The CBM drainage roadway of a 1413A longwall panel in Zhangji coal mine was excavated by a TBM and the deformation and failure behaviors of the roadway surrounding the rocks was different from these of conventional roadways due to different roadway geometries and excavation methods. 
A modified constitutive model and failure criterion of the roadway surrounding rocks was introduced within a numerical simulation to increase calculation precision. The optimized support design was proposed based on results of numerical simulation and it was verified by in-situ monitoring results. When the roof of the roadway was supported by rock bolts, the roadway convergence stabilized at $12 \mathrm{~mm}$ in 30 days after excavation and the axial force of rock bolts finally leveled off at a safety range after the installation of rock bolts. The calculation and monitoring results of roadway convergence were very close $(14.4$ and $12 \mathrm{~mm})$. Considering the diameter of the roadway $(4.5 \mathrm{~m})$, the calculation accuracy was accepted. Field applications suggested that the surrounding rock reached a stable state and the support design is appropriate. Supporting the roof of TBM-excavated coal mine roadways enables the safety of roadway excavation and speed of roadway supporting to be balanced.

This paper only focuses on the constitutive model and failure criterion of Zhangji sandstone under a cyclic loading-unloading stress path. The constitutive models and failure criterions of other rocks or under other stress paths can be obtained by using the research methodology proposed in this paper. The customized constitutive model and failure criterion can increase the simulation accuracy and efficiency of excavation safety controlling.

Author Contributions: Conceptualization, B.T. and H.C.; Data curation, C.R.; Formal analysis, B.T.; Funding acquisition, B.T.; Investigation, H.C.; Methodology, B.T. and T.Z.; Project administration, Y.T.; Resources, Y.T. and C.W.; Software, B.T.; Supervision, B.T. and H.C.; Validation, Z.Y. and C.W.; Visualization, B.T.; Writing-original draft, B.T.; Writing-review \& editing, H.C. All authors have read and agreed to the published version of the manuscript.

Funding: This research was funded by the National Natural Science Foundation of China (Grant No. 51804006), China Postdoctoral Science Foundation (Grant No. 2018M642503), Youth Fund of Anhui University of Science and Technology (Grant No. QN2017222), and Talent Introduction Fund of Anhui University of Science and Technology (Grant No. 11667). The authors gratefully acknowledge financial support of the above-mentioned agencies.

Conflicts of Interest: The authors declare no conflict of interest.

\section{References}

1. Huang, X.; Liu, Q.; Liu, B.; Liu, X.; Pan, Y.; Liu, J. Experimental Study on the Dilatancy and Fracturing Behavior of Soft Rock Under Unloading Conditions. Int. J. Civ. Eng. 2017, 15, 921-948. [CrossRef]

2. Li, Z.; Wang, E.; Ou, J.; Liu, Z. Hazard evaluation of coal and gas outbursts in a coal-mine roadway based on logistic regression model. Int. J. Rock Mech. Min. Sci. 2015, 80, 185-195. [CrossRef]

3. Erdogan, H.H.; Duzgun, H.S.; Selcuk-Kestel, A.S. Quantitative hazard assessment for Zonguldak Coal Basin underground mines. Int. J. Min. Sci. Technol. 2019, 29, 453-467. [CrossRef]

4. Krause, E.; Karbownik, M. Tests of methane desorption and emission from samples of hard coal in the context of mine closures through flooding. J. Sustain. Min. 2019, 18, 127-133. [CrossRef]

5. Kordos, J. Tests of new method of monitoring endogenous fire hazard in hard coal mines. J. Sustain. Min. 2019, 18, 134-141. [CrossRef]

6. Malkowski, P. The impact of the physical model selection and rock mass stratification on the results of numerical calculations of the state of rock mass deformation around the roadways. Tunn. Undergr. Space Technol. 2015, 50, 365-375. [CrossRef]

7. Zheng, Y.L.; Zhang, Q.B.; Zhao, J. Challenges and opportunities of using tunnel boring machines in mining. Tunn. Undergr. Space Technol. 2016, 57, 287-299. [CrossRef]

8. Mandal, P.K.; Das, A.J.; Kumar, N.; Bhattacharjee, R.; Tewari, S.; Kushwaha, A. Assessment of roof convergence during driving roadways in underground coal mines by continuous miner. Int. J. Rock Mech. Min. Sci. 2018, 108, 169-178. [CrossRef]

9. Huang, X.; Liu, Q.; Shi, K.; Pan, Y.; Liu, J. Application and prospect of hard rock TBM for deep roadway construction in coal mines. Tunn. Undergr. Space Technol. 2018, 73, 105-126. [CrossRef]

10. Gong, Q.; Liu, Q.; Zhang, Q. Tunnel boring machines (TBMs) in difficult grounds. Tunn. Undergr. Space Technol. Inc. Trenchless Technol. Res. 2016, 57. [CrossRef]

11. Li, Q.; Yang, R.; Li, J.; Wang, H.; Wen, Z. Strength and Cost Analysis of New Steel Sets as Roadway Support Project in Coal Mines. Adv. Mater. Sci. Eng. 2018, 2018, 3927843. [CrossRef] 
12. Wang, F.; Zhang, C.; Wei, S.; Zhang, X.; Guo, S. Whole section anchor-grouting reinforcement technology and its application in underground roadways with loose and fractured surrounding rock. Tunn. Undergr. Space Technol. Inc. Trenchless Technol. Res. 2016, 51, 133-143.

13. Cao, R.; Cao, P.; Lin, H. Support technology of deep roadway under high stress and its application. Int. J. Min. Sci. Technol. 2016, 26, 787-793. [CrossRef]

14. Huang, W.P.; Yuan, Q.; Tan, Y.L.; Wang, J.; Liu, G.L.; Qu, G.L.; Li, C. An innovative support technology employing a concrete-filled steel tubular structure for a 1000-m-deep roadway in a high in situ stress field. Tunn. Undergr. Space Technol. 2018, 73, 26-36. [CrossRef]

15. Stone, R. Design of primary ground support during roadway development using empirical databases. Int. J. Min. Sci. Technol. 2016, 26, 131-137. [CrossRef]

16. Yang, S.Q.; Chen, M.; Jing, H.W.; Chen, K.F.; Meng, B. A case study on large deformation failure mechanism of deep soft rock roadway in Xin'An coal mine, China. Eng. Geol. 2016, 217, 89-101. [CrossRef]

17. Gao, Z.W.; Kong, D.X.; Gao, C.H. Modeling and control of complex dynamic systems: Applied mathematical aspects. J. Appl. Math. 2012, 2012, 869792. [CrossRef]

18. Gao, Z.W.; Nguang, S.K.; Kong, D.X. Advances in Modelling, Monitoring, and Control for Complex Industrial Systems. Complexity 2019, 2019, 2975083. [CrossRef]

19. Gao, Z.W.; Saxen, H.; Gao, C.H. Guest Editorial: Special section on data-driven approaches for complex industrial systems. IEEE Trans. Ind. Inform. 2013, 9, 2210-2212. [CrossRef]

20. Tang, B.; Cheng, H.; Tang, Y.; Yao, Z.; Rong, C.; Wang, X.; Xue, W.; Guo, S. Experiences of gripper TBM application in shaft coal mine: A case study in Zhangji coal mine, China. Tunn. Undergr. Space Technol. 2018, 81, 660-668. [CrossRef]

21. Tang, B.; Cheng, H. Application of Distributed Optical Fiber Sensing Technology in Surrounding Rock Deformation Control of TBM-Excavated Coal Mine Roadway. J. Sens. 2018, 2018, 8010746. [CrossRef]

22. Huang, X.; Liu, Q.; Chen, L.; Pan, Y.; Liu, B.; Kang, Y.; Liu, X. Cutting force measurement and analyses of shell cutters on a mixshield tunnelling machine. Tunn. Undergr. Space Technol. 2018, 82, 325-345. [CrossRef]

23. Kang, Y.; Liu, Q.; Gong, G.; Wang, H. Application of a combined support system to the weak floor reinforcement in deep underground coal mine. Int. J. Rock Mech. Min. Sci. 2014, 71, 143-150. [CrossRef]

24. Kang, Y.; Liu, Q.; Xi, H.; Gong, G. Improved compound support system for coal mine tunnels in densely faulted zones: A case study of China's Huainan coal field. Eng. Geol. 2018, 240, 10-20. [CrossRef]

25. Sun, X.; Liu, Y.; Wang, J.; Li, J.; Sun, S.; Cui, X. Study on Three-Dimensional Stress Field of Gob-Side Entry Retaining by Roof Cutting without Pillar under Near-Group Coal Seam Mining. Processes 2019, 7, 552. [CrossRef]

26. Xie, B.; Yan, Z.; Du, Y.; Zhao, Z.; Zhang, X. Determination of Holmquist-Johnson-Cook Constitutive Parameters of Coal: Laboratory Study and Numerical Simulation. Processes 2019, 7, 386. [CrossRef]

27. Li, G.; Ma, F.; Liu, G.; Zhao, H.; Guo, J. A Strain-Softening Constitutive Model of Heterogeneous Rock Mass Considering Statistical Damage and its Application in Numerical Modeling of Deep Roadways. Sustainability 2019, 11, 2399. [CrossRef]

28. Liu, X.; Liu, Q.; Kang, Y.; Yucong, P. Improved Nonlinear Strength Criterion for Jointed Rock Masses Subject to Complex Stress States. Int. J. Geomech. 2018, 18, 04017164. [CrossRef]

29. Hajiabdolmajid, V.; Kaiser, P.K.; Martin, C.D. Modelling Brittle Failure of Rock. Int. J. Rock Mech. Min. Sci. 2002, 39, 731-741. [CrossRef]

30. Hajiabdolmajid, V.; Kaiser, P.K. Brittleness of rock and stability assessment in hard rock tunneling. Tunn. Undergr. Space Technol. 2003, 18, 35-48. [CrossRef]

31. Tang, B.; Hua, C.; Tang, Y.; Yao, Z.; Li, M.; Zheng, T.; Jian, L. Excavation damaged zone depths prediction for TBM-excavated roadways in deep collieries. Environ. Earth Sci. 2018, 77, 165. [CrossRef]

32. Yan, G.; Ma, Z.; Hu, Y. Study On Numerical Simulation of the Arrangement about Mining Roadway with Short Distance. Procedia Eng. 2011, 26, 301-310. 
33. Tsinidis, G.; Pitilakis, K.; Madabhushi, G. On the dynamic response of square tunnels in sand. Eng. Struct. 2016, 125, 419-437. [CrossRef]

34. Tang, B.; Cheng, H.; Tang, Y.; Yao, Z.; Rong, C.; Xue, W.; Lin, J. Application of a FBG-Based Instrumented Rock Bolt in a TBM-Excavated Coal Mine Roadway. J. Sens. 2018, 2018, 8191837. [CrossRef]

(C) 2020 by the authors. Licensee MDPI, Basel, Switzerland. This article is an open access article distributed under the terms and conditions of the Creative Commons Attribution (CC BY) license (http://creativecommons.org/licenses/by/4.0/). 